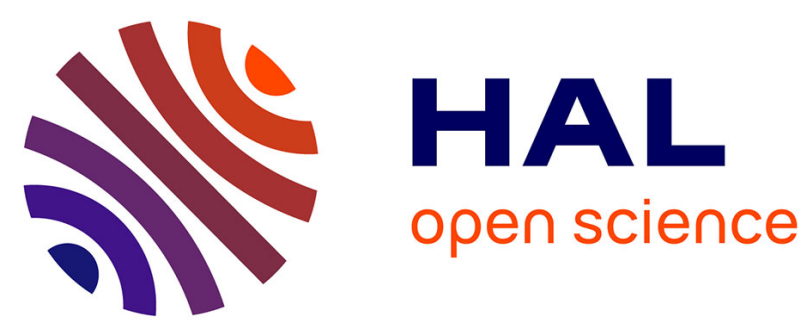

\title{
A Biodegradable Multifunctional Graphene Oxide Platform for Targeted Cancer Therapy
}

Cristina Martin, Amalia Ruiz, Sandeep Keshavan, Giacomo Reina, Diane

Murera, Yuta Nishina, Bengt Fadeel, Alberto Bianco

\section{To cite this version:}

Cristina Martin, Amalia Ruiz, Sandeep Keshavan, Giacomo Reina, Diane Murera, et al.. A Biodegradable Multifunctional Graphene Oxide Platform for Targeted Cancer Therapy. Advanced Functional Materials, 2019, 29 (39), pp.1901761. 10.1002/adfm.201901761 . hal-02328431

\section{HAL Id: hal-02328431 \\ https://hal.science/hal-02328431}

Submitted on 15 Nov 2019

HAL is a multi-disciplinary open access archive for the deposit and dissemination of scientific research documents, whether they are published or not. The documents may come from teaching and research institutions in France or abroad, or from public or private research centers.
L'archive ouverte pluridisciplinaire HAL, est destinée au dépôt et à la diffusion de documents scientifiques de niveau recherche, publiés ou non, émanant des établissements d'enseignement et de recherche français ou étrangers, des laboratoires publics ou privés. 


\section{A Biodegradable Multifunctional Graphene Oxide Platform for Targeted Cancer Therapy}

Cristina Martín, Amalia Ruiz, Sandeep Keshavan, Giacomo Reina, Diane Murera, Yuta Nishina, Bengt Fadeel, Alberto Bianco*

Dr. C. M., Dr. A. R., Dr. G. R, Dr. D. M., Dr. A. B

University of Strasbourg, CNRS, Immunology, Immunopathology and Therapeutic

Chemistry, UPR 3572, 67000 Strasbourg, France

E-mail: a.bianco@ibmc-cnrs.unistra.fr

Dr. S. K., Prof. B. F.

Institute of Environmental Medicine, Karolinska Institutet, 17177 Stockholm, Sweden Prof. Y. N.

Graduate School of Natural Science and Technology, Okayama University, Tsushimanaka, Kita-ku, Okayama 700-8530, Japan

Prof. Y. N.

Research Core for Interdisciplinary Sciences, Okayama University, Tsushimanaka, Kita-ku, Okayama 700-8530, Japan

The design of multifunctional materials able to both selectively deliver a drug into cells in a targeted manner and display an enhanced propensity for biodegradation is an important goal. Here, graphene oxide (GO) is functionalized with the chemotactic peptide $N$-FormylMethionyl-Leucyl-Phenylalanine (fMLP) known to interact with the formyl peptide receptor (FPR), which is expressed in different cancer cells, including cervical carcinoma cells. This study highlights the ability of GOfMLP for targeted drug delivery and cancer cell killing and the subsequent degradation capacity of the hybrid. Biodegradation is assessed by Raman spectroscopy and transmission electron microscopy (TEM). The results show that GOfMLP is susceptible to a faster myeloperoxidase (MPO) mediated degradation. The hybrid material, but not GO, is capable of inducing neutrophil degranulation with subsequent degradation, being the first study showing inducible neutrophil degradation by the nanomaterial itself with no prior activation of the cells. In addition, confocal imaging and flow cytometry using HeLa cells demonstrate that GOfMLP is able to deliver the chemotherapeutic agent doxorubicin faster into cells, inducing higher levels of apoptosis, when compared to non-functionalized 
GO. Our results reveal that GOfMLP is a promising carrier able to efficiently deliver anticancer drugs, being endowed with the ability to induce its own biodegradation.

\section{Introduction}

Novel drug delivery strategies for cancer therapy are receiving considerable attention. ${ }^{[1-3]}$ In particular, the design of site-directed (targeted) drug delivery systems that can concentrate a higher amount of drug in the tumor area, inducing less side effects for healthy tissues, is at the forefront of research. Among targeted release systems, platforms with nano-sized dimensions have exhibited great potential in biomedical applications. ${ }^{[4-6]}$ More specifically, graphenebased materials (GBMs) have been extensively studied in this context. ${ }^{[7,8]}$

Graphene is a single-layer sheet of $\mathrm{sp}^{2}$ hybridized carbon atoms with unique physical and chemical properties. ${ }^{[9]}$ The large family of GBMs shares this planar structure but have differences in size, thickness and oxidation state. ${ }^{[10]}$ Among them, GO is certainly the most studied for biological applications, particularly in drug and gene delivery. ${ }^{[11,12]}$ This is not surprising taking into account its high dispersibility in water, ${ }^{[13]}$ and its surface chemistry, which provides an excellent capability to graft a large number of substances such as metals, fluorescent probes or drugs, among others. ${ }^{[14]}$ On the other hand, the possible persistence of GO in the body raises doubts regarding the successful use of GBMs in clinical practice. However, we and others have shown the degradation ability of carbon nanomaterials incubated with different peroxidases. ${ }^{[15-18]}$ In addition, previous studies demonstrated in vivo degradation. ${ }^{[19]}$

GO has also been evidenced as one of the most favorable GBMs to be used as a platform for cancer therapy. ${ }^{[20]}$ Nevertheless, only a few works involve targeting ligands that recognize specific receptors on the tumor cell surface. ${ }^{[21,22]}$ For instance, Sun et al. ${ }^{[23]}$ covalently conjugated the B-cell specific antibody Rituxan (anti-CD20) to GO to selectively recognize and bind to B-cell lymphoma. Another example is the multi-functionalized GO synthesized by 
Yang et al. ${ }^{[24]}$ In this case, folic acid was used as the targeting ligand, and the results showed the potential of the hybrid to specifically transport the drug (i.e. doxorubicin) to SK3 cells. The peptide $N$-Formyl-Methionyl-Leucyl-Phenylalanine (fMLP) ${ }^{[25]}$ is an important chemoattractant molecule, which interacts with the formyl peptide receptor (FPR), expressed on immune cells ${ }^{[26,27]}$ and in different cancer cells, including cervical carcinoma cells. ${ }^{[28]}$ Moreover, fMLP (in combination with cytochalasin B) has been used in previous studies on the degradation of carbon nanotubes and $\mathrm{GBMs}^{[29,30]}$ due to its potential to activate neutrophils leading to degranulation and release of granule proteins such as myeloperoxidase (MPO).

In the present study, with the aim to prepare a "smart", targeted and biodegradable GO-based platform for drug delivery, we studied the effect of the functionalization of GO with the chemoattractant peptide fMLP. The hybrid obtained is a highly targeting nanomaterial able to efficiently deliver doxorubicin (DOX) in HeLa cancer cells and to self-stimulate the immune system to accelerate its biodegradation after its therapeutic action. We believe that the strategy described in this paper will be a reference for future studies of targeted drug delivery with translation in vivo.

\section{Results and discussion}

\subsection{Synthesis and characterization}

Targeting ligands are often employed in nanomedicine, as the passive accumulation in the tumor area due to the enhanced permeability and retention effect does not guarantee specific uptake by tumor cells. ${ }^{[31]}$ To improve cancer cell specific uptake of our nanocarrier, we have covalently attached the chemoattractant peptide fMLP to GO (GOfMLP). This peptide may target the cognate receptor, FPR on cancer cells. fMLP is also known to activate neutrophils, and may thereby serve to trigger the release of MPO. ${ }^{[29,30]}$ Therefore, we hypothesized that the degradation ability of GOfMLP would be enhanced while also serving to direct the hybrid and its cargo to cancer cells. 
The synthesis of GOfMLP was carried out using a GO, with lateral sizes in the range of $600 \pm 300 \mathrm{~nm},{ }^{[12,32]}$ as the starting material in a two-step protocol (Figure 1). The first step consisted on the formation of the GOTEG intermediate by the covalent functionalization of the surface of GO with 2,2'-(ethylenedioxy)bis(ethylamine) (diamino-TEG) in deionized water (Figure 1a). ${ }^{[33]}$ In the second step, fMLP peptide was covalently anchored to the GO surface through the TEG free amino groups, via a carbodiimide-mediated amidation (Figure $1 b)$.

Different techniques have been used to characterize the covalent functionalization of the GO surface with the peptide (Figure S1). The Kaiser test confirmed the presence of free amino groups on the GOTEG intermediate $(268 \mu \mathrm{mol} / \mathrm{g})$. After fMLP binding to GOTEG, the obtained Kaiser test value decreased, leaving $118 \mu \mathrm{mol} / \mathrm{g}$ of unreacted amino groups. In addition, thermogravimetric analysis (TGA), Fourier-transform infrared spectroscopy (FTIR) spectroscopy and X-ray photoelectron spectroscopy (XPS) corroborated fMLP conjugation (Figure S1). Full organic fMLP started degrading at $220^{\circ} \mathrm{C}$ (Figure S1a). The thermogravimetric curve of GO resulted in a main weight loss that initiates around $200{ }^{\circ} \mathrm{C}$ due to the decomposition of labile oxygenated moieties (Figure S1a). ${ }^{[12]}$ The curve obtained from GOfMLP showed an additional weight loss around $300{ }^{\circ} \mathrm{C}$ (Figure S1a), indicating the presence of different and more stable functional groups and bonds in the hybrid compared to GO (Figure S1a). The final weight losses obtained at $600{ }^{\circ} \mathrm{C}$ for GO and GOfMLP are $43.6 \%$ and $50.2 \%$, respectively, indicating for the latter the thermal degradation of the linked peptide moiety. FTIR spectra were also carried out (Figure S1b and S1c), and confirmed the existence of $\mathrm{OH}$ and $\mathrm{NH}_{2}\left(\sim 3400 \mathrm{~cm}^{-1}\right), \mathrm{CH}_{2}\left(\sim 3000 \mathrm{~cm}^{-1}\right), \mathrm{C}=\mathrm{O}\left(\sim 1700 \mathrm{~cm}^{-1}\right)$, and $\mathrm{C}=\mathrm{C}\left(\sim 1600 \mathrm{~cm}^{-1}\right)$ functional groups ${ }^{[33]}$ which are present in the structure of the three compounds. However, in the case of GOfMLP spectrum, the rise in the band assigned to C-N stretch $\left(\sim 1011 \mathrm{~cm}^{-1}\right)$ demonstrated an increase in the number of amino groups in GOfMLP conjugate compared to GO or GOTEG. In addition, the FTIR spectrum of GOfMLP revealed a new peak compared 
to the spectrum of GOTEG, due to the appearance of the characteristic amide stretching at $\sim 1650 \mathrm{~cm}^{-1},{ }^{[23]}$ verifying the amide bond formation between GOTEG and fMLP. Finally, Figure S1d and S1e show the results obtained from the XPS analysis. A slight increase in the value of sulfur content was observed in the case of GOfMLP $(0.9 \pm 0.09 \%)$ compared to nonfunctionalized GO $(0.71 \pm 0.01 \%)$, confirming the presence of the peptide in the GOfMLP hybrid. The yield of the process was $\sim 56 \%$.

\subsection{In vitro biodegradability}

Although carbon nanomaterials have been postulated as being structurally persistent, various studies have recently demonstrated that peroxidases are able to catalyze the oxidative degradation of some nanostructures. ${ }^{[30,34,35]}$ On the other hand, though a few articles have investigated both biodistribution and tumor targeting ability, ${ }^{[36]}$ the nano-carrier biodegradation capacity has not been thoroughly investigated. Prior to any clinical trial, the fate of any nano-carrier and its eventual persistence in the body must be addressed. ${ }^{[37-39]}$ Having conjugated fMLP to the surface of GO, the next objective of our work was to assess the biodegradation capacity of GOfMLP. For this purpose, we carried out the degradation experiments by incubating GOfMLP with human MPO, an enzyme that is found in high abundance in neutrophils and is secreted when these cells encounter pathogens. ${ }^{[40]}$ The degradation reaction was carried out in phosphate buffer solution at $37^{\circ} \mathrm{C}$ for $24 \mathrm{~h}$. The enzyme was replenished every $5 \mathrm{~h}$ and $\mathrm{H}_{2} \mathrm{O}_{2}$ was added every hour to maintain the same catalytic activity throughout the experiment. ${ }^{[15,30]}$ Non-functionalized GO was used as the control to test the role of the peptide moiety in the biodegradation process. The first evidence of degradation was the change in the color intensity of both GO and GOfMLP suspensions after $24 \mathrm{~h}$ of incubation with the enzyme (Figure S2). The variation in the color of the dispersions has been previously reported as a clear sign of biodegradation. ${ }^{[29,41]}$ Kagan et al. ${ }^{[29]}$ demonstrated that the incubation of human MPO with carbon nanotubes, without $\mathrm{H}_{2} \mathrm{O}_{2}$, did not inactivate the enzyme. Therefore, we decided to analyze the interaction 
of MPO with the surface of both GO and GOfMLP sheets by polyacrylamide gel electrophoresis (Figure S3). MPO was incubated with both nanomaterials separately at room temperature for $24 \mathrm{~h}$ before the electrophoresis. Densitometric analysis of the resulting gel bands was quantified by ImageJ software. The analysis showed a decrease in the intensity of the gel bands corresponding to the enzyme incubated with the GO and GOfMLP compared to the control (MPO alone). Values of $89.13 \pm 4.75 \%$ and $85.85 \pm 5.85 \%$ of band intensities were obtained for GO and GOfMLP, respectively, assuming 100\% of band intensity for MPO alone used as control (a molecular weight ladder was also run for reference). This result pointed out that MPO binds both GO and GOfMLP, reducing the amount of protein migrating into the gel.

To investigate the changes in the structure and the morphology of the GOfMLP and GO sheets after incubation with MPO, TEM analysis at different time points was carried out. Figure 2 shows the morphology of GO and GOfMLP sheets after 24 h of incubation, in absence/presence of MPO. In the case of control samples, a homogeneous and regular sheet structure was found for both nanomaterials. In contrast, porous GO and GOfMLP sheets were observed when samples were incubated with MPO, in agreement with previous studies. ${ }^{[15,29,30]}$ This result confirmed the degradation capacity of both GO and GOfMLP samples. It is noteworthy that after $24 \mathrm{~h}$, only a partial degradation had taken place and the holes observed in the flakes were not uniformly distributed in all sheets. Indeed, after the incubation in the presence of MPO, two different sets of sheets were observed: (I) some sheets which have not been completely degraded, and other sheets (II) that clearly showed extensive damage on the surfaces due to degradation.

Raman spectroscopy was also used to investigate the degradation process of the GO and GOfMLP structures (Figure 3). The main features in the Raman spectra of carbon materials are the so-called D and G bands, which correspond to disordered carbon and to the $\mathrm{sp}^{2}$ tangential mode, respectively. The D band appears at $\sim 1350 \mathrm{~cm}^{-1}$ and the $\mathrm{G}$ band arises at 
$\sim 1600 \mathrm{~cm}^{-1} \cdot{ }^{[42]}$ Both bands are clearly visible in the average spectra from the control samples, which were incubated in the absence of MPO (Figure 3). However, it is known that both Raman features become less intense when the carbon nanomaterial undergoes degradation due to the progressive loss of the native structure. ${ }^{[29,30]}$ The intensity of both $\mathrm{D}$ and $\mathrm{G}$ bands was significantly reduced in GO and GOfMLP, after $24 \mathrm{~h}$ of enzymatic reaction compared to the control samples. Nevertheless, the degradation of GO and GOfMLP is not uniformly distributed. As in the case of the TEM analysis for the morphological characterization, two classes of Raman spectra are displayed (Figure 3). The first series of spectra (I) were similar to the control ones, presenting well defined D and G bands, and corresponding to the sheets that were not degraded. On the other hand, in a second set of spectra (II) the intensity of the main peaks was drastically decreased, corresponding to the damaged sheets due to the oxidation/degradation of the nanomaterial. $\mathrm{I}_{\mathrm{D}} / \mathrm{I}_{\mathrm{G}}$ intensities were also calculated from every average spectrum in order to quantify the number of defects (Figure S4). The GO average spectrum displayed an $I_{D} / I_{G}$ of 0.66 . However, the average spectrum corresponding to the $D$ and the $\mathrm{G}$ band intensities from the degraded GOfMLP sample reached the baseline, suggesting a faster and more efficient degradation compared to GO. A conceivable explanation could be the possible better interaction of the fMLP moiety with the enzyme compared to the non-functionalized GO (Figure $\mathrm{S} 3$ ). The $\mathrm{I}_{\mathrm{D}} / \mathrm{I}_{\mathrm{G}}$ value for both controls and non-degraded sheets, was 1.03 in all cases. The decrease in $\mathrm{I}_{\mathrm{D}} / \mathrm{I}_{\mathrm{G}}$ in the case of the $24 \mathrm{~h}$ treated GO sample showed the formation of more amorphous carbon structures or $\mathrm{sp}^{2}$ noncrystalline carbon phase. This latter degradation pathway could be due to a higher defect density as it has been previously reported. ${ }^{[15,42]}$

\subsection{Inducible neutrophil degradation}

To evaluate the biodegradation under physiological conditions, we isolated primary neutrophils from human donors. Cell viability of neutrophils exposed to GO and GOfMLP was determined using the Alamar blue assay. Both GO and GOfMLP displayed some toxicity 
at $3 \mathrm{~h}$ of incubation with the cells, with $78 \%$ and $69 \%$ viability, respectively, at the highest concentration (Figure 4a). It is important to note, however, that neutrophils are programmed to undergo cell death, unlike transformed cell lines. ${ }^{[43]}$ We then assessed for MPO release in GO and GOfMLP exposed cells by performing staining of the cells using FITC-conjugated MPO-specific antibodies. ${ }^{[29]}$ Upon degranulation, MPO is released from the cells and can be detected following its attachment on the cell surface. Cells incubated with fMLP+cytochalasin B (CB) (known to cause degranulation) were included as a positive control. GOfMLP caused a clear increase in MPO expression corresponding to $~ 1.4$ fold increase in fluorescence (Figure $4 \mathrm{~b}$ ). In the presence of $\mathrm{fMLP}+\mathrm{CB}$, we observed a 3 fold increase in fluorescence in comparison to the control. It is worth noting that we used $10 \mathrm{nM}$ fMLP as a positive control while $50 \mu \mathrm{g} \cdot \mathrm{mL}^{-1}$ of GOfMLP corresponds to approx. $50 \%$ of this amount of fMLP. This may explain the differences observed between GOfMLP and fMLP+CB. Moreover, once MPO is released, it is likely that at least some fraction is adsorbed onto the surface of the GOfMLP hybrid. Importantly, GO alone did not trigger any MPO expression.

Our previous reports have demonstrated that neutrophils are capable of enzymatic degradation of various carbonaceous nanomaterials. ${ }^{[29,30,41,44]}$ Indeed, we recently reported that neutrophils are capable of mediating biodegradation of GO upon ex vivo activation of the cells with fMLP+CB. ${ }^{[41]}$ Here, freshly isolated primary human neutrophils were incubated with GO and GOfMLP in the absence of fMLP and CB. The samples were then subjected to Raman confocal microspectroscopic analysis. The results obtained showed that the characteristic feature of GO, i.e., the intensity of the $\mathrm{D}$ band $\left(\sim 1350 \mathrm{~cm}^{-1}\right)$ and of the $\mathrm{G}$ peak band $\left(\sim 1590 \mathrm{~cm}^{-1}\right)$ remained unchanged at the indicated time points for non-functionalized GO (Figure 5a). Thus, the GO average spectrum displayed an $\mathrm{I}_{\mathrm{D}} / \mathrm{I}_{\mathrm{G}}$ of $\sim 1$ similar to the control spectra. On the other hand, in the GOfMLP treated samples we observed that at $3 \mathrm{~h}$ and $6 \mathrm{~h}$, the peak intensities were drastically reduced in comparison to control, suggesting biodegradation of GOfMLP (Figure 5b). Since fMLP has been used in previous studies on the 
degradation of $\mathrm{GBMs}^{[29,30]}$ due to its potential to activate neutrophils leading to degranulation and release of granule proteins such as MPO, the fMLP moiety anchored to the GO surface could be the responsible of the GOfMLP biodegradation due to a higher MPO secretion compared to the one of the GO exposed cells. Overall, these results showed that primary human neutrophils can rapidly degrade GOfMLP, which is in line with the observation that GOfMLP, but not GO, is capable of triggering MPO release in these cells.

\subsection{Drug loading/release studies}

After confirming the biodegradation capacity of our system, we decided to test the ability of GOfMLP as a nano-vehicle for drug delivery. DOX is a well-established anticancer drug ${ }^{[45]}$ and the supramolecular stacking of this drug on carbon-based nanomaterials for biomedical applications has been extensively investigated (Table S1). In this context, we chose DOX mainly due to its easy adsorption onto GO surfaces via hydrogen bonding and electrostatic interactions, its efficacy in cancer treatment and its spectrophotometric and fluorescent properties, which allow its tracking and quantification by several spectroscopic techniques. A quantitative study was carried out to determine the drug loading on GO and GOfMLP. The physisorption of the drug was studied at different DOX:nanomaterial (DOX:NM) ratios, in order to find the maximum drug loading capacity whilst preventing drug wastage. GO and GOfMLP were dispersed in PBS (at $0.1 \mathrm{mg} / \mathrm{mL}$ ) and then stirred in the presence of DOX at 4 ${ }^{\circ} \mathrm{C}$ for $24 \mathrm{~h}$ in the dark. Different DOX:NM ratios (mg:mg), from 0.25 to 2, were tested. The resulting complexes were collected and washed by centrifugation $\left(4^{\circ} \mathrm{C}, 8000 \mathrm{rpm}\right)$ until the supernatant was clear. The amount of unbound DOX in the solution was determined by highperformance liquid chromatography (HPLC), measuring the absorbance at $483 \mathrm{~nm}$. Figure S5 displays the percentage of DOX bound to both GO and GOfMLP at different ratios. DOX:NM $=0.25$ was deemed the best condition for preparing GO-DOX and GOfMLP-DOX conjugates. The DOX percentage was higher for GO than for GOfMLP. Indeed, the drug loading contents resulted in $0.18 \mathrm{mg}$ of DOX per $\mathrm{mg}$ of GO and $0.09 \mathrm{mg}$ of DOX per $\mathrm{mg}$ of 
GOfMLP. These values are in agreement with other previously reported DOX loading contents for GO ${ }^{[46]}$ We believe that a possible steric hindrance, exerted by the peptide, and a less available surface in GOfMLP are the reasons for the decrease in the amount of bound DOX obtained for the peptide-based hybrid compared to non-functionalized GO. In fact, the crucial role of the GBM surface chemistry has been previously reported, ${ }^{[10]}$ and it is crucial to control and characterize the functional groups which are present in each GBM to compare their behavior patterns, including as drug delivery systems.

In order to ensure that DOX will be released from the nanomaterial platform once it is inside the cells, we carried out preliminary test tube experiments. The mechanism of release has been described as a pH-dependent decomplexation of DOX from GBMs due to the partial protonation/deprotonation of the six-membered daunosamine sugar. ${ }^{[37]}$ In fact, this would be intracellularly crucial because the drug remains complexed to the nanomaterial until the conjugate enters into the endosome, where the $\mathrm{pH}$ is acidic, leading to the protonation of the amino groups. Subsequently, the interaction between DOX and the carrier is weakened and, consequently, the drug is released. The drug release profile of GO-DOX and GOfMLP-DOX was evaluated in PBS solutions at both physiological $(\mathrm{pH}=7.4)$ and acidic $(\mathrm{pH}=5.0)$ conditions (Figure S6). The samples were incubated at $37^{\circ} \mathrm{C}$ whilst stirring at $300 \mathrm{rpm}$ and aliquots were taken at different time points to quantify the DOX release. According to the literature, a higher amount of DOX is released at an acidic $\mathrm{pH}$ compared to a neutral $\mathrm{pH}$. The release in acidic conditions was $\sim 3$ times higher for GOfMLP, likely caused by a lower affinity of the drug for the surface of the peptide-modified GO and, in consequence, due to the characteristic and different GO and GOfMLP surface chemistries. Both platforms showed a bimodal release profile. Hence, an initial burst of the drug was observed within $1 \mathrm{~h}$ followed by the extended release segment liberating the drug over the following $23 \mathrm{~h}$. A very slow release of the drug ( $1-2 \%$ of the drug per day) was detected after a week (data not shown). It 
is noteworthy that the gradual release of the drug could help in overcoming its toxic effects by avoiding unwanted DOX delivery before reaching the site of interest.

\subsection{In vitro cellular uptake studies}

The final goal of this work was to evaluate the ability of GOfMLP to specifically deliver DOX into cancer cells. To track and estimate the DOX release in vitro, we initially carried out confocal microscopy analyses. Free DOX can be easily observed via confocal microscopy exciting at $561 \mathrm{~nm}$ and recording at $600-660 \mathrm{~nm}$. Although DOX adsorbed onto the GO surface is strongly quenched, free DOX molecules are visible in this range of wavelengths. ${ }^{[46]}$ For this set of experiments, HeLa cells were incubated at the equivalent concentration of DOX $(10 \mu \mathrm{M})$ using GO-DOX, GOfMLP-DOX and DOX alone as control. In cells treated with the drug alone, DOX was internalized after $8 \mathrm{~h}$ of incubation and localized mainly inside the nucleus (Figure 6). Free DOX treatment showed the highest intensity, due to its efficient internalization in cells in a short time. GO-DOX showed a negligible drug internalization, meanwhile a higher presence of DOX was recorded in the GOfMLP-DOX complex. Confocal microscopy was also used to estimate the quantity of DOX inside the nucleus. For this purpose, unstained HeLa cells were treated with the same amount of DOX $(10 \mu \mathrm{M})$ in all formulations. DOX quantification was estimated after $8 \mathrm{~h}$ of incubation using FIJI software according to the literature (Figure 7). ${ }^{[47]}$

The treatment with free DOX showed the highest internalization of the drug inside the nuclei, and this value was designated as $100 \%$ taking into account that there are no diffusion barriers regarding desorption from the graphene-based platform (Figure 7a). GOfMLP-DOX showed a significantly higher drug signal than GO-DOX (Figure 7b and c, respectively). Densitometric analysis of the images showed that GO and GOfMLP delivered $9 \pm 8 \%$ and 30 $\pm 12 \%$ of the drug, respectively, into the nuclei compared to the DOX alone (100 $\pm 27 \%)$

(Figure 7d). Overall, based on our confocal microscopy characterization, as expected, free DOX treatment is able to assure the maximum quantity of DOX in the nuclei. Meanwhile, the 
GOfMLP-DOX is able to deliver three times more drug than GO-DOX. As mentioned before, DOX is a soluble drug that is rapidly internalized in HeLa cells. In the latter case, DOX release is determined by the desorption process of the drug molecules from the carbon nanomaterial surface. The interaction between DOX and the GO surface is stabilized mainly via electrostatic interactions and hydrogen bonding. ${ }^{[48]}$ As observed in the release profiles (Figure S6), DOX desorption is negligible at neutral $\mathrm{pH}$ and is triggered in an acidic environment. ${ }^{[48]}$ We think that most of the DOX is released inside of the lysosomes where the low $\mathrm{pH}$ turns on the drug desorption. Compared to non-functionalized GO, GOfMLP undoubtedly showed better DOX release features and this is most probably due to the peptide functionalization modifying its surface chemistry. The presence of the fMLP moiety on one side reduces the loading efficiency of the material (as seen in the drug loading values) but on the other hand may help to enhance the drug release profile in the adequate biological environment (Figure S6). In addition, fMLP can be recognized by the membrane FPR receptor in HeLa cells, probably enhancing the GOfMLP internalization in this cancerous cell line, making it an extremely interesting targeting carrier. Conjugation of DOX with a biospecific targeting graphene oxide slows down its release profile in vitro and could improve the pharmacokinetic behavior of the drug in future clinical trials.

\subsection{Cancer cell killing}

By functionalizing GO with the fMLP peptide, we were able not only to modify its physicochemical properties as a drug delivery system for DOX, but also its uptake by HeLa cells and the intracellular release of the drug. This change in the surface chemistry of the GO likely affects the efficiency and toxicity of the complex compared to the unmodified GO and the free drug. The cytotoxicity of both DOX loaded nano-carriers was evaluated through the degree of cell survival by flow cytometry using the standard assay with a violet fixable viability dye (FVD) and an annexin V-FITC assay for the detection of apoptotic cells. The analysis of cytotoxicity after $8 \mathrm{~h}$ of incubation with the nanomaterials showed that viability 
was not significantly reduced by the treatments (Figure 8a). After 24 h of incubation, a doseresponse effect in the viability of cultured HeLa cells was observed (Figure 8c).

Corroborating the internalization pattern observed by confocal microscopy, GO-DOX and GOfMLP-DOX affected cell survival less than DOX alone. Nevertheless, GOfMLP-DOX exhibited a significant $10 \%$ increase in toxicity compared to GO-DOX. These results were also confirmed by evaluating the number of apoptotic cells with annexin V-FITC. ${ }^{[49]}$ The levels of phosphatidylserine (PS) detected were low in every treatment group at $8 \mathrm{~h}$ of incubation with a noticeable increase at $20 \mu \mathrm{M}$ of DOX alone (Figure 8b). The annexin V staining results are in accordance with the faster internalization pattern of the soluble drug observed previously by confocal microscopy, compared with the DOX loaded onto the delivery platforms. After $24 \mathrm{~h}$, all cells treated with free DOX are positive for annexin V staining while a dose response effect is observed in the groups treated with the DOX loaded nanomaterials (Figure 8d). Compared to non-functionalized GO, GOfMLP showed a 20\% improvement in triggering apoptosis in HeLa cells. As the tumor cell killing is rather rapid, this anticancer action is likely compatible with the subsequent biodegradability that neutrophils or macrophages can exert following the recruitment and activation of these cells. In order to support the higher drug delivery to cancer HeLa cells by GOfMLP-DOX mediated by fMLP in this cell line, we investigated if the internalization mechanism for GOfMLP was favored by FPR receptor. For this set of experiments, we incubated HeLa cells with GOfMLP-DOX in the absence and in the presence of fMLP $(0.5 \mathrm{mg} / \mathrm{mL})$ and EDTA $(10 \mu \mathrm{M})$ in order to saturate the receptor with the peptide and sequester the calcium with EDTA, inhibiting $\mathrm{Ca}^{2+}$ responses, and consequently the activity of kinase proteins involved in the mechanism. ${ }^{[50,51]}$ After $24 \mathrm{~h}$ of incubation, we washed the cells and rinsed with fresh media. GOfMLP-DOX was able to efficiently deliver DOX into HeLa cells. Besides when excess of free peptide is present into the media doxorubicin is not delivered intracellularly (Figure S8). This finding suggests that DOX is scarcely released in cell culture media and that the 
GOfMLP uptake mechanism is favored by FPR receptor. These data agree with different studies using graphene oxide-based platforms for DOX delivery in vitro, where it was observed a decrease of viability between $20-50 \%$ after exposure to drug concentrations around $20 \mu \mathrm{M}$ for $24 \mathrm{~h} \cdot{ }^{[52-54]}$ Nevertheless, we would like to underline the differences regarding the physicochemical characteristics of the carriers, their specific functionalization targeting different ligands on cell membranes or the differences in drug sensitivity according to the cell line used in the different studies.

\section{Conclusion}

In summary, we have prepared a GO-peptide adduct with both biodegradability and targeting drug delivery features. The resulting hybrid, GOfMLP, was well-characterized and its degradation capacity was confirmed by TEM and Raman. Hence, the hybrid, with sub-micron lateral dimensions, displayed biodegradability in vitro using human MPO as well as inducible degradation ex vivo upon incubation with human neutrophils. It should be noted that, the pharmacokinetics, the biodistribution and the drug delivery efficiency of other systems based on GO, with comparable size dimensions, have been previously reported in the literature. ${ }^{[55,56]}$ It is also noteworthy that the addition of the peptide-based moiety to the GO surface did not interfere with the oxidation/degradation process. Moreover, GOfMLP was able to trigger neutrophil release of MPO with subsequent degradation, while this was not seen for GO. Previous studies have shown that GO may undergo neutrophil degradation when the cells are pre-activated. ${ }^{[41]}$ However, this is the first study showing inducible neutrophil degradation by the nanomaterial itself (no prior activation of the cells). It is important to note that exaggerated neutrophil degranulation may lead to tissue damage. ${ }^{[57]}$ Further work using relevant in models is needed to determine the safety profile of GOfMLP. Furthermore, GOfMLP loaded with doxorubicin was able to bind to the cell membrane, very likely through the FPR receptor, and to enhance drug internalization in the cancer cells compared to GO. The specific interaction between the material and the cells allowed a significant improvement in 
different variables, such as faster recognition and internalization by the cells, more efficient release of the drug in subcellular acidic environment, a 3 fold increase in the drug delivered into the nucleus, and higher cytotoxic effects and apoptosis levels on the cells. Furthermore, the versatility of the synthetic strategy makes it possible to design tailored GO conjugates for other receptors of interest. Altogether, these results demonstrate that the prepared ad hoc functionalized GO is a powerful biodegradable platform for drug delivery. Our results on targeting cancer cells in vitro, together with the rapid biodegradability, make GOfMLP a highly interesting candidate for future studies on cancer therapy.

\section{Experimental Section}

Materials: 1-Ethyl-3-(3-dimethylaminopropyl)carbodiimide hydrochloride (EDC $\cdot \mathrm{HCl}), \mathrm{N}$ hydroxysuccinimide (NHS), diethylenetriaminepentaacetic acid (DTPA), DOX and 2,2'(ethylenedioxy)bis(ethylamine) (TEG) were purchased from Sigma Aldrich (Lyon, France). PBS (0.0067 $\mathrm{M} \mathrm{PO}_{4}$ without calcium and magnesium) was purchased from LONZA (Strasbourg, France). Ultrapure water was prepared from a Milli-Q® Direct 8/10 System (Millipore). MPO derived from human neutrophils (Athens Research and Technology, Athens, Georgia, USA) with an activity of $>200 \mathrm{U} \cdot \mathrm{mg}^{-1}$.

Synthesis of GOTEG: GOTEG was prepared via epoxide ring-opening reaction starting from GO. ${ }^{[33,58,59]}$ Diamino-TEG $(350 \mu \mathrm{L})$ was added to a $17 \mathrm{~mL}$ dispersion of $\mathrm{GO}\left(1 \mathrm{mg} \cdot \mathrm{mL}^{-1}\right) .{ }^{[32]}$ The reaction mixture was homogenized and stirred for 3 days at room temperature. After centrifugation $\left(5000 \mathrm{rpm}, 25 \mathrm{~min}, 4^{\circ} \mathrm{C}\right.$ ), the precipitate was dispersed in $\mathrm{H}_{2} \mathrm{O}$, sonicated in a water bath for a few minutes and centrifuged. This sequence was repeated until the $\mathrm{pH}$ of the supernatant was neutral. The functionalized GO was dialyzed against MilliQ water for 3 days and then lyophilized.

Synthesis of $f M L P$ : peptide was assembled using optimized Fmoc chemistry protocols with a multichannel peptide synthesizer. ${ }^{[60]}$ Formyl group was coupled using formic acid manually with standard conditions (BOP reagent, HOBt, and diisopropylethylamine in 
dimethylformamide). Side-chain deprotection and cleavage of the peptide from the solid support was performed by treatment with reagent $\mathrm{K}(88 \% \mathrm{TFA} v / \mathrm{v}, 2 \%$ Triisopropylsilane $\mathrm{v} / \mathrm{v}$, $5 \%$ dithiothreitol $\mathrm{w} / \mathrm{v}, 5 \%$ water $\mathrm{v} / \mathrm{v}$ ) for $150 \mathrm{~min}$ at $20^{\circ} \mathrm{C}$. Peptide was purified by reversedphase HPLC (RP-HPLC) using a preparative HPLC system (Waters) on a Nucleosil $\mathrm{C}_{18}(1 \times 30$ $\mathrm{cm}$ ) column, (Macherey Nagel). The elution was achieved with a linear gradient of aqueous $0.1 \%$ TFA (A) and $0.08 \%$ TFA in acetonitrile (B) at a flow rate of $6 \mathrm{~mL} \cdot \mathrm{min}^{-1}$ with UV detection at $230 \mathrm{~nm}$. The purity of the peptide was controlled by analytical RP-HPLC on a Waters instrument (Waters Alliance) with a Nucleosil C18 $5 \mu \mathrm{m}$ column $(150 \times 4.6 \mathrm{~mm})$ using a linear gradient of $0.1 \%$ TFA in water and acetonitrile containing $0.08 \%$ TFA at a flow rate of $1.2 \mathrm{~mL} \cdot \mathrm{min}^{-1}$. The integrity of the peptide was assessed by LC/MS using a Thermo Finigan LCQ. Molecular weight calculated/observed: 437/437.8d (Figure S7).

Synthesis of GOfMLP: to activate the carboxyl groups of fMLP, EDC $\cdot \mathrm{HCl}(370 \mu \mathrm{g}, 1.2 \mathrm{eq})$ was added to $700 \mu \mathrm{g}$ ( 1 eq) of fMLP, previously solubilized in DMF (5 mL). The mixture was stirred at $0{ }^{\circ} \mathrm{C}$ for $30-40 \mathrm{~min}$. Then, $276 \mu \mathrm{g}$ (1.5 eq) of NHS were added to the mixture and this mixture was stirred for $45 \mathrm{~min}$. Finally, $5 \mathrm{mg}$ of GOTEG were added and the mixture was stirred at room temperature overnight. After washing the reaction mixture with DMF $(3 \times 20$ $\mathrm{mL}$ ) by filtering it on a polytetrafluoroethylene omnipore membrane filter with $0.45 \mu \mathrm{m}$ pore size, the solvent was exchanged with MilliQ water $(5 \times 20 \mathrm{~mL})$, thus obtaining GOfMLP in aqueous dispersion.

Characterization of GO, fMLP and GOfMLP: thermogravimetric analyses of the three samples were performed using TGA1 (Mettler Toledo) apparatus from $30^{\circ} \mathrm{C}$ to $800{ }^{\circ} \mathrm{C}$ with a ramp of $10^{\circ} \mathrm{C} \cdot \mathrm{min}^{-1}$ under $\mathrm{N}_{2}$ using a flow rate of $50 \mathrm{~mL} \cdot \mathrm{min}^{-1}$ and platinum pans. FTIR spectroscopy spectra were measured on a Perkin Elmer Spectrum One ATR-FT-IR spectrometer. $\mathrm{KBr}$ pellets were prepared for each of the three samples. Finally, X-ray photoelectron spectroscopy analyses were carried out using a Thermo Scientific KAlpha Xray photoelectron spectrometer equipped with an aluminium X-ray source (energy 1.4866 
$\mathrm{keV}$ ) and working at pressure of $10^{-8}-10^{-9}$ mbar in the main chamber. Three different locations of each sample were analyzed. The averages and the standard deviations were calculated from the three different scans that were carried out in each sample (GO, fMLP and GOfMLP).

Degradation of $\mathrm{GO}$ and $\mathrm{GOfMLP}$ by $\mathrm{MPO} / \mathrm{H}_{2} \mathrm{O}_{2}$ : following the protocol of Kurapati et al., ${ }^{[15]}$ mixtures of $160 \mu \mathrm{g}$ of each nanomaterial and $100 \mu \mathrm{g}$ of MPO were dispersed in $1 \mathrm{~mL}$ of 50 mM phosphate buffer containing $140 \mathrm{mM} \mathrm{NaCl}$ and $100 \mu \mathrm{M}$ DTPA. $\mathrm{H}_{2} \mathrm{O}_{2}$ was added at a dose of $200 \mu \mathrm{M} \cdot \mathrm{h}^{-1}$ for $5 \mathrm{~h}$. MPO was replenished every $5 \mathrm{~h}$ and the mixture was incubated at $37^{\circ} \mathrm{C}$ for $24 \mathrm{~h}$. The control experiments were carried out following the same protocol but with adding only $\mathrm{H}_{2} \mathrm{O}_{2}$.

Transmission electron microscopy: six $\mu \mathrm{L}$ of each suspension of GO and GOfMLP were dropped on a carbon coated copper grid and dried for 30 min under a lamp. The grids were then washed with MilliQ water for $30 \mathrm{~min}$ and dried for $24 \mathrm{~h}$ before the analysis. All the samples were analyzed by a Hitachi H7500 microscope (Tokyo, Japan).

Raman spectroscopy: ten $\mu \mathrm{L}$ of each suspension of GO and GOfMLP were dropped on silicon substrates and dried for $24 \mathrm{~h}$ before the analysis. Raman spectra were acquired by using a Renishaw inVia microscope equipped with $532 \mathrm{~nm}$ laser. A $100 \times$ objective lens was employed, and the laser power and the exposure time were $1 \%$ and $10 \mathrm{~s}$, respectively, in all the experiments. All the samples were prepared in the same manner, from the same aliquots, and using the same Raman conditions, meaning that the differences between non-degraded (I) and degraded (II) set of spectra cannot be due to differences in the concentration, but due to partial degradation of both GO and GOfMLP. Different areas of the sample were tested and at least 10 different spectra were used to represent the average spectra showed in this paper.

Polyacrylamide gel electrophoresis: MPO was incubated with both nanomaterials separately at room temperature for $24 \mathrm{~h}$. Then, Laemmli buffer was added to the mixture and the samples 
were loaded on a Mini PROTEAN®TGXTM 10\% precasted gel (BioRad). The electrophoresis was carried out under non-reducing conditions. MPO was used as a control. The gels were stained with Coomassie Brilliant Blue R250 and the resulting gel bands were analyzed by ImageJ software. ${ }^{[33]}$

Neutrophil isolation: neutrophils were isolated from buffy coats of healthy human blood donors (Karolinska University Hospital, Stockholm, Sweden) as previously described. ${ }^{[43]}$ The samples are completely anonymized and for this reason no specific ethical committee approval is required. Briefly, neutrophils were isolated from healthy donors by density gradient centrifugation at $423 \times \mathrm{g}$ for 30 min using Lymphoprep ${ }^{\mathrm{TM}}$ (Axis Shield, Oslo, Norway) followed by gradient sedimentation in a 5\% dextran solution and hypotonic lysis of residual erythrocytes. To study degradation, freshly isolated neutrophils $\left(10^{6}\right.$ cells $\left.\cdot \mathrm{mL}^{-1}\right)$ were incubated in phenol red-free RPMI-1640 culture medium (Sigma Aldrich) supplemented with $2 \mathrm{mM}$ L-glutamine, $100 \mathrm{U} \cdot \mathrm{mL}^{-1}$ penicillin and $100 \mathrm{mg} \cdot \mathrm{mL}^{-1}$ streptomycin without serum and incubated in $5 \% \mathrm{CO}_{2}$ at $37^{\circ} \mathrm{C}$ with $\mathrm{GO}$ and GOfMLP at $50 \mu \mathrm{g} \cdot \mathrm{mL}^{-1}$. Freshly isolated neutrophils were exposed with GO and GOfMLP at indicated concentrations. Before the neutrophils are collected at a specific time point, they were washed with sterile luke-warm PBS and centrifuged at 270xg. The cell pellet was collected and re-suspended in PBS and stored at $-80{ }^{\circ} \mathrm{C}$ for further analysis.

Cytotoxicity assessment: freshly isolated primary human neutrophils were seeded in 96-well plates in phenol red-free RPMI-1640 cell medium at a density of $10^{6}$ cells $\cdot \mathrm{mL}^{-1}$ and exposed to GO and GOfMLP at the indicated concentrations, or were maintained in cell medium alone (negative control) at $37{ }^{\circ} \mathrm{C}$, in a humidified $5 \% \mathrm{CO}_{2}$ incubator. Figure $\mathrm{S} 9$ shows the colloidal stability of both GO and GOfMLP in distilled water, PBS buffer and cell culture medium, as previously reported in the literature for related graphene-based materials. ${ }^{[61-63]}$ Alamar Blue (AB) assay was performed for cytotoxicity assessment of the biodegradation samples. ${ }^{[64]} \mathrm{AB}$ dye was purchased from Thermo Scientific (Sweden). After the exposure period, the AB 
assay was performed according to the manufacturer's instruction. Briefly, AB reagent $(10 \%$ [v/v] solution) was added to each well. After $2 \mathrm{~h}$ of incubation at $37^{\circ} \mathrm{C}$, fluorescence was measured at the respective excitation and emission wavelength of $531 \mathrm{~nm}$ and $595 \mathrm{~nm}$ using a Tecan Infinite F200 plate reader. AB solution in the RPMI-1640 cell medium complete medium alone was included as blank. The experiment was performed with at least three biological replicates and two technical replicates for each concentration of GO and GOfMLP. Results were expressed as percentage cell viability versus control. To control for interference, the GO and GOfMLP degradation reaction mixture was maintained in cell-free medium and mixed with the $\mathrm{AB}$ dye; no interference was observed (data not shown).

Neutrophil degranulation: GO and GOfMLP samples were assessed for the amount of MPO release, based on flow cytometric analysis. MPO was stained by fluorescein isothiocyanate (FITC)-labeled antibody according to the manufacturer's instructions (Biolegend, San Diego, CA). Briefly, freshly isolated primary human neutrophils were seeded in phenol red-free RPMI-1640 cell medium at a density of $10^{6}$ cells $\cdot \mathrm{mL}^{-1}$ and exposed to GO and GOfMLP at 50 $\mu \mathrm{g} \cdot \mathrm{mL}^{-1}$. As a positive control, cells were incubated with fMLP $(10 \mathrm{nM})$ and cytochalasin B $\left(5 \mu \mathrm{g} \cdot \mathrm{mL}^{-1}\right)$. All the samples were incubated with $20 \mu \mathrm{L}$ FITC-conjugated MPO antibody for $30 \mathrm{~min}$ in the dark at room temperature. Samples were analyzed using a BD LSRFortessa ${ }^{\mathrm{TM}}$ cell analyzer (BD Bioscience, CA).

Confocal Raman analysis: Raman analysis was performed on samples drop-casted onto a glass slide and dried. Raman analysis was performed as previously described ${ }^{[17]}$ using a confocal Raman microspectroscopy (WITec alpha300 system, Germany) with a laser of 532 $\mathrm{nm}$ wavelength set at an integration time of $0.5 \mathrm{~s}$ and $600 \times$ magnification. The scan area for each sample was adjusted to $50 \times 50 \mu \mathrm{m}$. For determination of the intensities of the D-band (second order double resonant mode activated by defects, $\sim 1354 \mathrm{~cm}^{-1}$ ) and G-band (tangential C-C stretching modes, $\sim 1582 \mathrm{~cm}^{-1}$ ). The spectrum of each sample is an average of 10.000 spectra obtained from a scan size of $50 \mu \mathrm{m} \times 50 \mu \mathrm{m}$. 
DOX loading and release profile: DOX loading onto GO and GOfMLP was achieved by stirring each nanomaterial dispersion in $\mathrm{PBS}\left(0.1 \mathrm{mg} \cdot \mathrm{mL}^{-1}\right)$ at a physiological $\mathrm{pH}$ in the presence of the drug $\left(4^{\circ} \mathrm{C}, 24 \mathrm{~h}\right.$ in dark conditions). We tested different DOX:NM ratios (mg:mg), from 0.25 to 2 (DOX:NM $=0.25$ was chosen to prepare GO-DOX and GOfMLP-DOX conjugates for the delivery studies). After mixing overnight, the extra DOX molecules were removed by centrifugation $\left(4{ }^{\circ} \mathrm{C}, 5938 \times \mathrm{g}\right)$ and the pellet was washed thoroughly until the supernatant became color-free. The loading content of the drug (mg DOX loaded:mg NM) was quantified by measuring the absorbance of the supernatants at $483 \mathrm{~nm}$ by analytical RP-HPLC with a Nucleosil 100-5 Waters $C_{18}$ reverse phase HPLC column and a Waters Alliance e2695 separation module. The column was used with $1.2 \mathrm{~mL} \cdot \mathrm{min}^{-1}$ flow rate of a gradient from 5 to $65 \%$ of $\mathrm{B}\left(\mathrm{A}=\mathrm{H}_{2} \mathrm{O} / 0.1 \% \mathrm{TFA} ; \mathrm{B}=\mathrm{CH}_{3} \mathrm{CN} / 0.08 \% \mathrm{TFA}\right)$ for $20 \mathrm{~min}$, according to the standard calibration curve of free DOX. The obtained GO-DOX and GOfMLP-DOX were redispersed in PBS $\left(0.1 \mathrm{mg} \cdot \mathrm{mL}^{-1}\right.$, according to the initial concentration of $\left.\mathrm{NM}\right)$ at two different $\mathrm{pHs}$ $(\mathrm{pH}=7.4$ and $\mathrm{pH}=5.0)$ for subsequent tests of DOX delivery. Then, both complex dispersions were incubated at $37{ }^{\circ} \mathrm{C}$ under oscillation at $300 \mathrm{rpm}$ by using an Eppendorf ThermoMixer ${ }^{\circledR}$ instrument to induce drug release. This cycle was repeated at specific time points to calculate the cumulative weight and relative percentage of the released DOX as a function of incubation time.

Cancer cell culture: HeLa (human cervical adenocarcinoma) cells were cultured as monolayers in Dulbecco's modified Eagle medium supplemented with $10 \mu \mathrm{g} \cdot \mathrm{mL}^{-1}$ gentamycin (Lonza BioWhittaker), 10 mM HEPES (Lonza BioWhittaker), 0.05 mM $\beta$-mercaptoethanol (Lonza BioWhittaker) and 10\% FBS, in a humidified incubator $\left(37^{\circ} \mathrm{C}, 5 \% \mathrm{CO}_{2}\right)$. The cells were purchased from ATCC at passage 4 and were kept in liquid nitrogen until use. For cell killing experiments, cells were seeded in 12 -well plates $\left(1 \times 10^{5}\right.$ cells/well, $\left.1 \mathrm{~mL} / \mathrm{well}\right)$. The formulations were diluted in the cell culture media at different concentrations and 
subsequently cells were exposed for 8 or $24 \mathrm{~h}$ to the treatments. HeLa cells were also incubated with GOfMLP-DOX in the absence and in the presence of fMLP $(0.5 \mathrm{mg} / \mathrm{mL})$ and EDTA $(10 \mu \mathrm{M})$. After $24 \mathrm{~h}$ of incubation, the cells were washed and rinsed with fresh media. For confocal microscopy, the cells were seeded in 8-well chamber slides (Thermo Scientific) ( $1 \times 10^{4}$ cells/well, $500 \mu \mathrm{L} /$ well). Cells were left to grow until $70-80 \%$ confluency and were subsequently exposed for up to $24 \mathrm{~h}$.

Cancer cell killing: cell viability was determined by flow cytometry using the standard assay with FVD (Fixable Viability Dyes, violet, Invitrogen), either 8 or $24 \mathrm{~h}$ after exposure to the materials. The supernatant was aspirated and discarded and the cells were washed twice with PBS. Cells were detached from the plates using a solution of $0.25 \%$ Trypsin/0.53 mM EDTA. The cells were washed with PBS, $2 \%$ FBS and then were incubated $\left(20 \mathrm{~min}, 4{ }^{\circ} \mathrm{C}\right)$ with the dye (dil. 1:2000). To evaluate their apoptotic state, the cells were stained with annexin V labeled with FITC (556419, BD Bioscience) as per the instructions from the supplier. Thereafter, the cells were washed with PBS, $2 \%$ FBS and resuspended in $300 \mu \mathrm{L}$, and immediately acquired on the cytometer (Beckman Coulter, Fullerton, CA). At least 10000 cells were counted for each sample, and experiments were performed in triplicates. Flow cytometry data were generated using FlowJo software (FlowJo LLC, software version 7.6.5. Ashland, OR, USA). Cell viability (\%) was calculated as [(A/B) $\times 100]$, where A and B are the number of dead cells of treated and control cells respectively. Values represent mean \pm SD (n $=3$ ).

Cell uptake studies: confocal images have been captured with a Microscope Zeiss Axio Observer Z1 Confocal Spinning disk equipped with 63 or $100 \times$ oil objective and $40 \times$ for quantification. Green Cell-Mask was recorded using $488 \mathrm{~nm}$ laser and recording in the green channel (505-555 nm), while DOX was recorded using $561 \mathrm{~nm}$ laser in the red channel (600$660 \mathrm{~nm})$. Images have then been treated with FIJI software. For quantification, Region Of 
Interest (ROI) analysis was applied. ROIs have been selected accordingly for each cell. The intensity average has been calculated after blank subtraction.

Statistical analysis: all statistical analyses were performed using the Graph-Pad Prism 7 software (San Diego, CA, USA). Details of the data analysis used are explained in GraphPad Prism 7 user's guide (https://www.graphpad.com/guides/prism/7/user-guide/index.htm).

\section{Supporting Information}

Supporting Information is available from the Wiley Online Library or from the author.

\section{Acknowledgements}

The authors gratefully acknowledge the financial support from the EU GRAPHENE Flagship project (no. 785219), and the Agence Nationale de la Recherche (ANR) through the LabEx project Chemistry of Complex Systems (ANR-10-LABX-0026_CSC). This work was partly supported by the Centre National de la Recherche Scientifique (CNRS), the International Center for Frontier Research in Chemistry (icFRC), the JST PRESTO, and the JSPS KAKENHI (Science of Atomic Layers (SATL), Grant number 16H00915). The authors thank

C. Royer and V. Demais for TEM analysis at the Plateforme Imagerie in Vitro at the Center of Neurochemistry (Strasbourg, France). We thank Mizanur Rahman, Karolinska Institutet, for advice on the flow cytometry data analysis. We also thank Dr. Olivier Chaloin for the synthesis of fMLP performed at the Institut de Biologie Moléculaire et Cellulaire (Strasbourg, France).

\section{References}

[1] S. Merino, C. Martín, K. Kostarelos, M. Prato, E. Vázquez, ACS Nano 2015, 9, 4686.

[2] S.-Y. Qin, A.-Q. Zhang, S.-X. Cheng, L. Rong, X.-Z. Zhang, Biomaterials 2017, 112, 234. 
[3] J. I. Hare, T. Lammers, M. B. Ashford, S. Puri, G. Storm, S. T. Barry, Adv. Drug Deliv. Rev. 2017, 108, 25.

[4] T. Kong, L. Hao, Y. Wei, X. Cai, B. Zhu, Cell Prolif. 2018, 51, e12488.

[5] W. Zhang, Z. Zhang, Y. Zhang, Nanoscale Res. Lett. 2011, 6, 555.

[6] T. Zhou, X. Zhou, D. Xing, Biomaterials 2014, 35, 4185.

[7] G. Reina, J. M. González-Domínguez, A. Criado, E. Vázquez, A. Bianco, M. Prato, Chem. Soc. Rev. 2017, 46, 4400.

[8] G. Modugno, C. Ménard-Moyon, M. Prato, A. Bianco, Br. J. Pharmacol. 2015, 172, 975.

[9] A. K. Geim, K. S. Novoselov, Nat. Mater. 2007, 6, 183.

[10] B. Fadeel, C. Bussy, S. Merino, E. Vázquez, E. Flahaut, F. Mouchet, L. Evariste, L. Gauthier, A. J. Koivisto, U. Vogel, C. Martín, L. G. Delogu, T. Buerki-Thurnherr, P. Wick, D. Beloin-Saint-Pierre, R. Hischier, M. Pelin, F. Candotto Carniel, M. Tretiach, F. Cesca, F. Benfenati, D. Scaini, L. Ballerini, K. Kostarelos, M. Prato, A. Bianco, ACS Nano 2018, 12, 10582.

[11] S. K. K, M. Das Modak, P. Paik, J. Nanomedicine Res. 2017, 5, 1.

[12] N. D. Q. Chau, G. Reina, J. Raya, I. A. Vacchi, C. Ménard-Moyon, Y. Nishina, A. Bianco, Carbon 2017, 122, 643.

[13] D. Konios, M. M. Stylianakis, E. Stratakis, E. Kymakis, J. Colloid Interface Sci. 2014, $430,108$.

[14] Y. Wang, Z. Li, J. Wang, J. Li, Y. Lin, Trends Biotechnol. 2011, 29, 205.

[15] R. Kurapati, J. Russier, M. A. Squillaci, E. Treossi, C. Ménard-Moyon, A. E. Del RioCastillo, E. Vazquez, P. Samorì, V. Palermo, A. Bianco, Small 2015, 11, 3985.

[16] G. P. Kotchey, S. A. Hasan, A. A. Kapralov, S. H. Ha, K. Kim, A. A. Shvedova, V. E. Kagan, A. Star, Acc. Chem. Res. 2012, 45, 1770.

[17] F. T. Andón, A. A. Kapralov, N. Yanamala, W. Feng, A. Baygan, B. J. Chambers, K. 
Hultenby, F. Ye, M. S. Toprak, B. D. Brandner, A. Fornara, J. Klein-Seetharaman, G. P. Kotchey, A. Star, A. A. Shvedova, B. Fadeel, V. E. Kagan, Small 2013, 9, 2720.

[18] K. Bhattacharya, R. El-Sayed, F. T. Andón, S. P. Mukherjee, J. Gregory, H. Li, Y. Zhao, W. Seo, A. Fornara, B. Brandner, M. S. Toprak, K. Leifer, A. Star, B. Fadeel, Carbon 2015, 91, 506.

[19] C. M. Girish, A. Sasidharan, G. S. Gowd, S. Nair, M. Koyakutty, Adv. Healthc. Mater. 2013, $2,1489$.

[20] G. Gonçalves, M. Vila, M.-T. Portolés, M. Vallet-Regi, J. Gracio, P. A. A. P. Marques, Adv. Healthc. Mater. 2013, 2, 1072.

[21] O. C. Farokhzad, R. Langer, ACS Nano 2009, 3, 16.

[22] N. Bertrand, J. Wu, X. Xu, N. Kamaly, O. C. Farokhzad, Adv. Drug Deliv. Rev. 2014, $66,2$.

[23] X. Sun, Z. Liu, K. Welsher, J. T. Robinson, A. Goodwin, S. Zaric, H. Dai, Nano Res. 2008, $1,203$.

[24] X. Yang, Y. Wang, X. Huang, Y. Ma, Y. Huang, R. Yang, H. Duan, Y. Chen, J. Mater. Chem. 2011, 21, 3448.

[25] M. A. Panaro, V. Mitolo, Immunopharmacol. Immunotoxicol. 1999, 21, 397.

[26] P. R. Taylor, L. Martinez-Pomares, M. Stacey, H.-H. Lin, G. D. Brown, S. Gordon, Annu. Rev. Immunol. 2005, 23, 901.

[27] S. Gunaseelan, K. Gunaseelan, M. Deshmukh, X. Zhang, P. J. Sinko, Adv. Drug Deliv. Rev. 2010, 62, 518.

[28] G. Cao, Z. Zhang, Cancer Manag. Res. 2018, 10, 5855.

[29] V. E. Kagan, N. V. Konduru, W. Feng, B. L. Allen, J. Conroy, Y. Volkov, I. I. Vlasova, N. A. Belikova, N. Yanamala, A. Kapralov, Y. Y. Tyurina, J. Shi, E. R. Kisin, A. R. Murray, J. Franks, D. Stolz, P. Gou, J. Klein-Seetharaman, B. Fadeel, A. Star, A. A. Shvedova, Nat. Nanotechnol. 2010, 5, 354. 
[30] R. Kurapati, S. P. Mukherjee, C. Martín, G. Bepete, E. Vázquez, A. Pénicaud, B. Fadeel, A. Bianco, Angew. Chemie Int. Ed. 2018, 57, 11722.

[31] A. Bogdanov, S. Wright, E. Marecos, A. Bogdanova, C. Martin, P. Petherick, R. Weissleder, J. Drug Target. 1997, 4, 321.

[32] N. Morimoto, T. Kubo, Y. Nishina, Sci. Rep. 2016, 6, 21715.

[33] R. Kurapati, F. Bonachera, J. Russier, A. R. Sureshbabu, C. Ménard-Moyon, K. Kostarelos, A. Bianco, 2D Mater. 2017, 5, 015020.

[34] G. P. Kotchey, B. L. Allen, H. Vedala, N. Yanamala, A. A. Kapralov, Y. Y. Tyurina, J. Klein-Seetharaman, V. E. Kagan, A. Star, ACS Nano 2011, 5, 2098.

[35] R. Kurapati, C. Backes, C. Ménard-Moyon, J. N. Coleman, A. Bianco, Angew. Chemie 2016, 128, 5596.

[36] Z. Liu, W. Cai, L. He, N. Nakayama, K. Chen, X. Sun, X. Chen, H. Dai, Nat. Nanotechnol. 2007, 2, 47.

[37] T. Sun, M. Zheng, Z. Xie, X. Jing, Mater. Chem. Front. 2017, 1, 354.

[38] T. Kong, L. Hao, Y. Wei, X. Cai, B. Zhu, Cell Prolif. 2018, 51, e12488.

[39] M. Mohajeri, B. Behnam, A. Sahebkar, J. Cell. Physiol. 2018, 234, 298.

[40] V. Witko-Sarsat, P. Rieu, B. Descamps-Latscha, P. Lesavre, L. Halbwachs-Mecarelli, Lab. Invest. 2000, 80, 617.

[41] S. P. Mukherjee, A. R. Gliga, B. Lazzaretto, B. Brandner, M. Fielden, C. Vogt, L. Newman, A. F. Rodrigues, W. Shao, P. M. Fournier, M. S. Toprak, A. Star, K. Kostarelos, K. Bhattacharya, B. Fadeel, Nanoscale 2018, 10, 1180.

[42] A. C. Ferrari, Solid State Commun. 2007, 143, 47.

[43] B. Fadeel, A. Ahlin, J. I. Henter, S. Orrenius, M. B. Hampton, Blood 1998, 92, 4808.

[44] K. Bhattacharya, C. Sacchetti, R. El-Sayed, A. Fornara, G. P. Kotchey, J. A. Gaugler, A. Star, M. Bottini, B. Fadeel, Nanoscale 2014, 6, 14686.

[45] Z. Liu, A. C. Fan, K. Rakhra, S. Sherlock, A. Goodwin, X. Chen, Q. Yang, D. W. 
Felsher, H. Dai, Angew. Chemie 2009, 48, 7668.

[46] T. Zhou, X. Zhou, D. Xing, Biomaterials 2014, 35, 4185.

[47] H. Kawai, Y. Minamiya, M. Kitamura, I. Matsuzaki, M. Hashimoto, H. Suzuki, S. Abo, Cancer 1997, 79, 214.

[48] S. Wu, X. Zhao, Y. Li, Q. Du, J. Sun, Y. Wang, X. Wang, Y. Xia, Z. Wang, L. Xia, Mater. (Basel, Switzerland) 2013, 6, 2026.

[49] V. E. Kagan, B. Gleiss, Y. Y. Tyurina, V. A. Tyurin, C. Elenström-Magnusson, S.-X. Liu, B. Serinkan, A. Arroyo, J. Chandra, S. Orrenius, B. Fadeel, J Immunol Ref. 2002, $169,487$.

[50] J. W. Putney, T. Tomita, Adv. Biol. Regul. 2012, 52, 152.

[51] T. D. Werry, G. F. Wilkinson, G. B. Willars, Biochem. J. 2003, 374, 281.

[52] X. Zhao, L. Liu, X. Li, J. Zeng, X. Jia, P. Liu, Langmuir 2014, 30, 10419.

[53] Y. Lv, L. Tao, S. W. Annie Bligh, H. Yang, Q. Pan, L. Zhu, Mater. Sci. Eng. C 2016, $59,652$.

[54] Y. Fong, C.-H. Chen, J.-P. Chen, Y. T. Fong, C.-H. Chen, J.-P. Chen, Nanomaterials 2017, 7, 388.

[55] D. A. Jasim, C. Ménard-Moyon, D. Bégin, A. Bianco, K. Kostarelos, Chem. Sci. 2015, $6,3952$.

[56] D. Yang, L. Feng, C. A. Dougherty, K. E. Luker, D. Chen, M. A. Cauble, M. M. Banaszak Holl, G. D. Luker, B. D. Ross, Z. Liu, H. Hong, Biomaterials 2016, 104, 361.

[57] B. S. van der Veen, M. P. J. de Winther, P. Heeringa, Antioxid. Redox Signal. 2009, 11, 2899.

[58] G. Reina, A. Ruiz, D. Murera, Y. Nishina, A. Bianco, ACS Appl. Mater. Interfaces 2019, 11, 7695 .

[59] I. A. Vacchi, C. Spinato, J. Raya, A. Bianco, C. Ménard-Moyon, Nanoscale 2016, 8, 
13714.

[60] J. Neimark, J. P. Briand, Pept. Res. 1993, 6, 219.

[61] A. Pattammattel, P. Pande, D. Kuttappan, M. Puglia, A. K. Basu, M. A. Amalaradjou, C. V. Kumar, Langmuir 2017, 33, 14184.

[62] V. León, J. M. González-Domínguez, J. L. G. Fierro, M. Prato, E. Vázquez, Nanoscale 2016, 8,14548 .

[63] I. Chowdhury, M. C. Duch, N. D. Mansukhani, M. C. Hersam, D. Bouchard, Environ. Sci. Technol. 2013, 47, 6288.

[64] S. P. Mukherjee, K. Kostarelos, B. Fadeel, Adv. Healthc. Mater. 2018, 7, 1700815. 
(a)

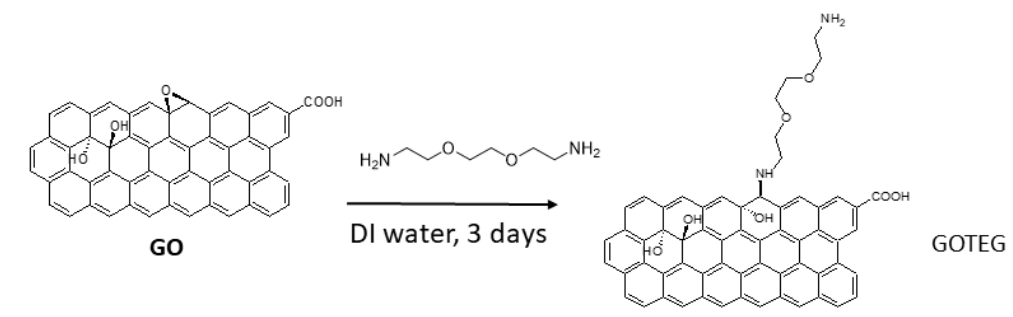

(b)

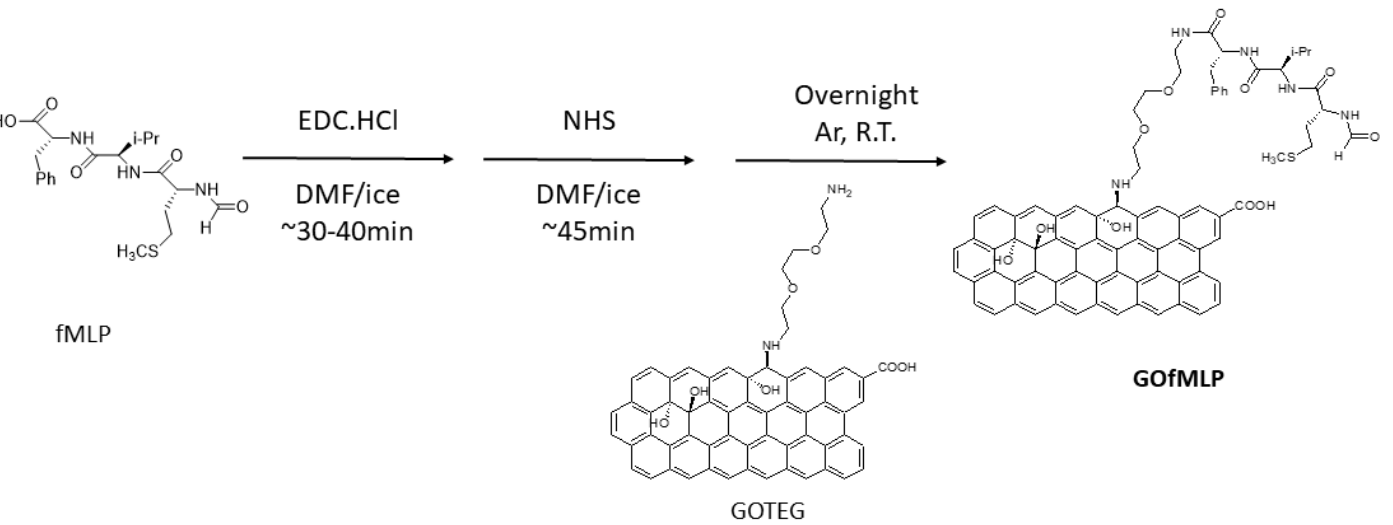

Figure 1. Scheme of the synthesis of GOfMLP.

$24 \mathrm{~h}$
$\mathrm{H}_{2} \mathrm{O}_{2}$
CONTROL

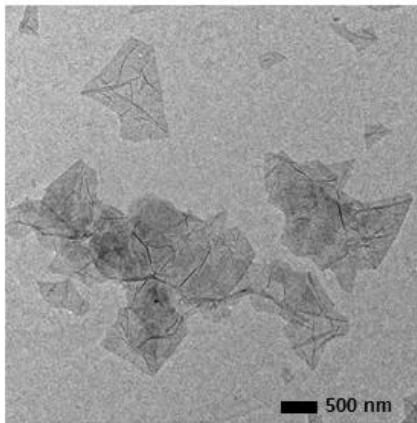

GO

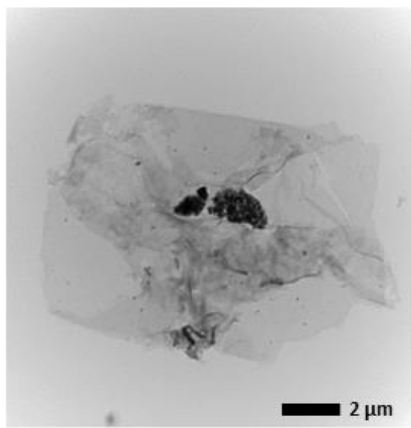

$24 \mathrm{~h}$ MPO $\mathrm{H}_{2} \mathrm{O}_{2}$

(I) NON-DEGRADED
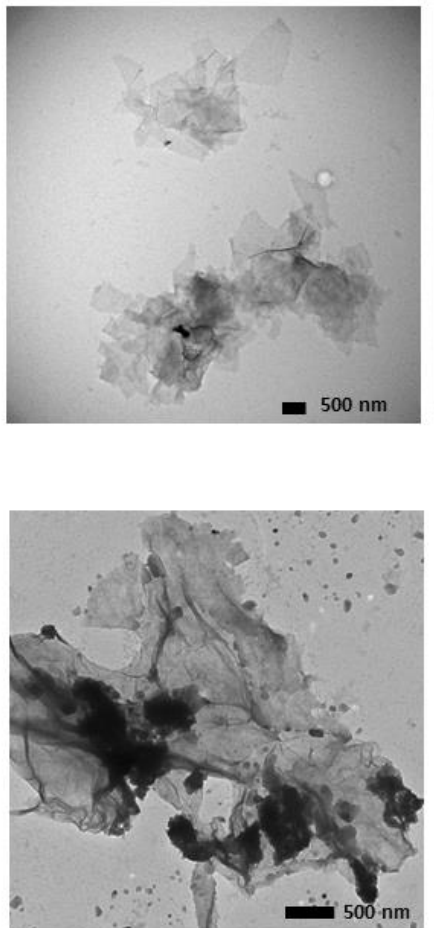

$24 \mathrm{~h}$ MPO $\mathrm{H}_{2} \mathrm{O}_{2}$

(II) DEGRADED
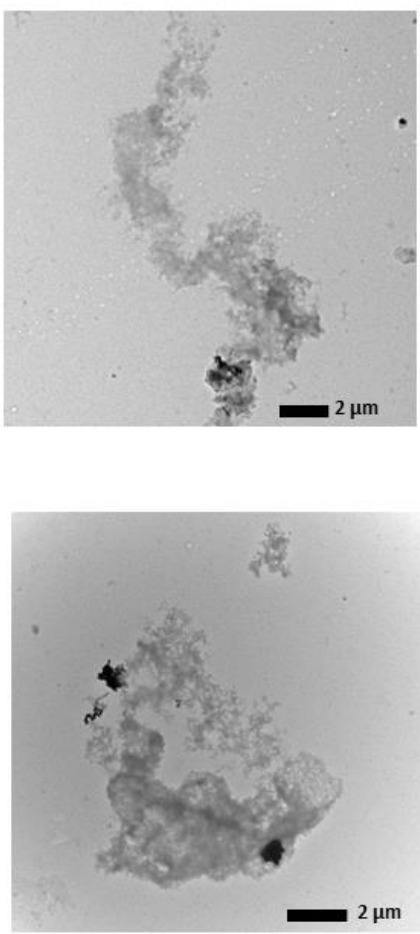

Figure 2. TEM images of GO and GOfMLP after treatment with $\mathrm{H}_{2} \mathrm{O}_{2}$ (control) or $\mathrm{MPO} / \mathrm{H}_{2} \mathrm{O}_{2}$ for $24 \mathrm{~h}$. 

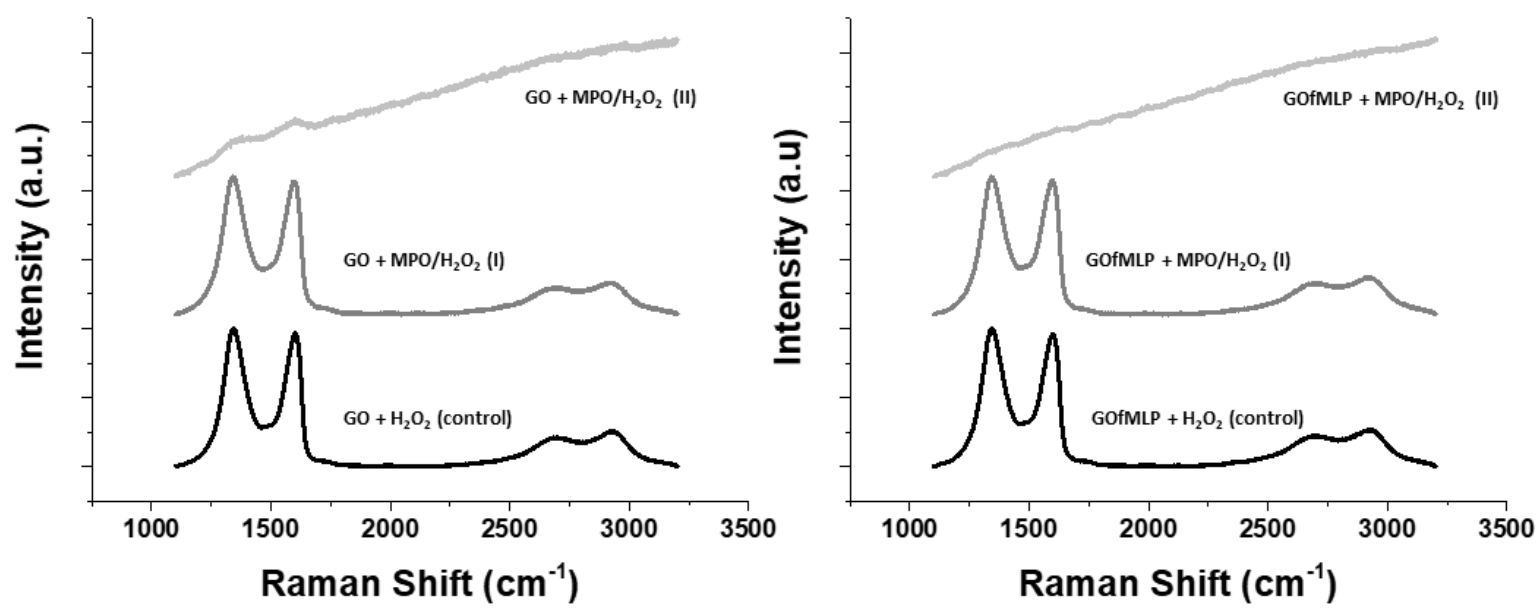

Figure 3. Average Raman spectra of GO (left) and GOfMLP (right) samples. Controls, nondegraded (I) and degraded (II) set of spectra are represented in both cases.

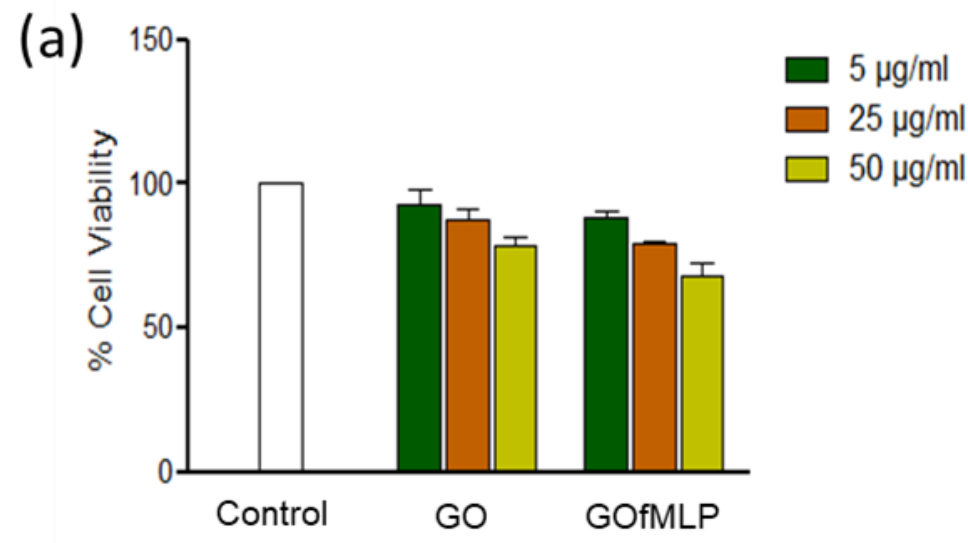

(b)

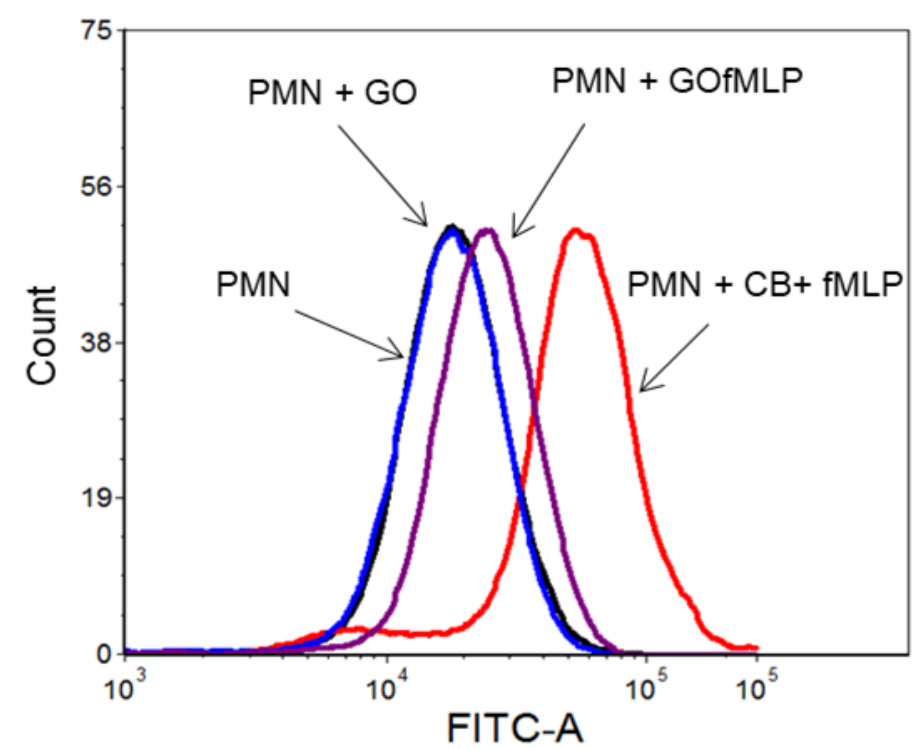

Figure 4. Neutrophil (PMN, polymorphonuclear neutrophils) viability and degranulation in response to GO vs. GOfMLP. (a) Neutrophils were exposed for $3 \mathrm{~h}$ to GO and GOfMLP at the indicated concentrations and cell viability was measured by using the Alamar Blue assay. Data shown are mean values \pm S.D. $(n=3)$. (b) Neutrophils were exposed to GO and GOfMLP at $50 \mu \mathrm{g} \cdot \mathrm{mL}^{-1}$ for $3 \mathrm{~h}$ and analyzed by flow cytometry following staining with FITC-MPO 
antibodies. Neutrophils exposed to $\mathrm{fMLP}+\mathrm{CB}$ were included as a positive control for MPO release, and untreated neutrophils served as a negative control.
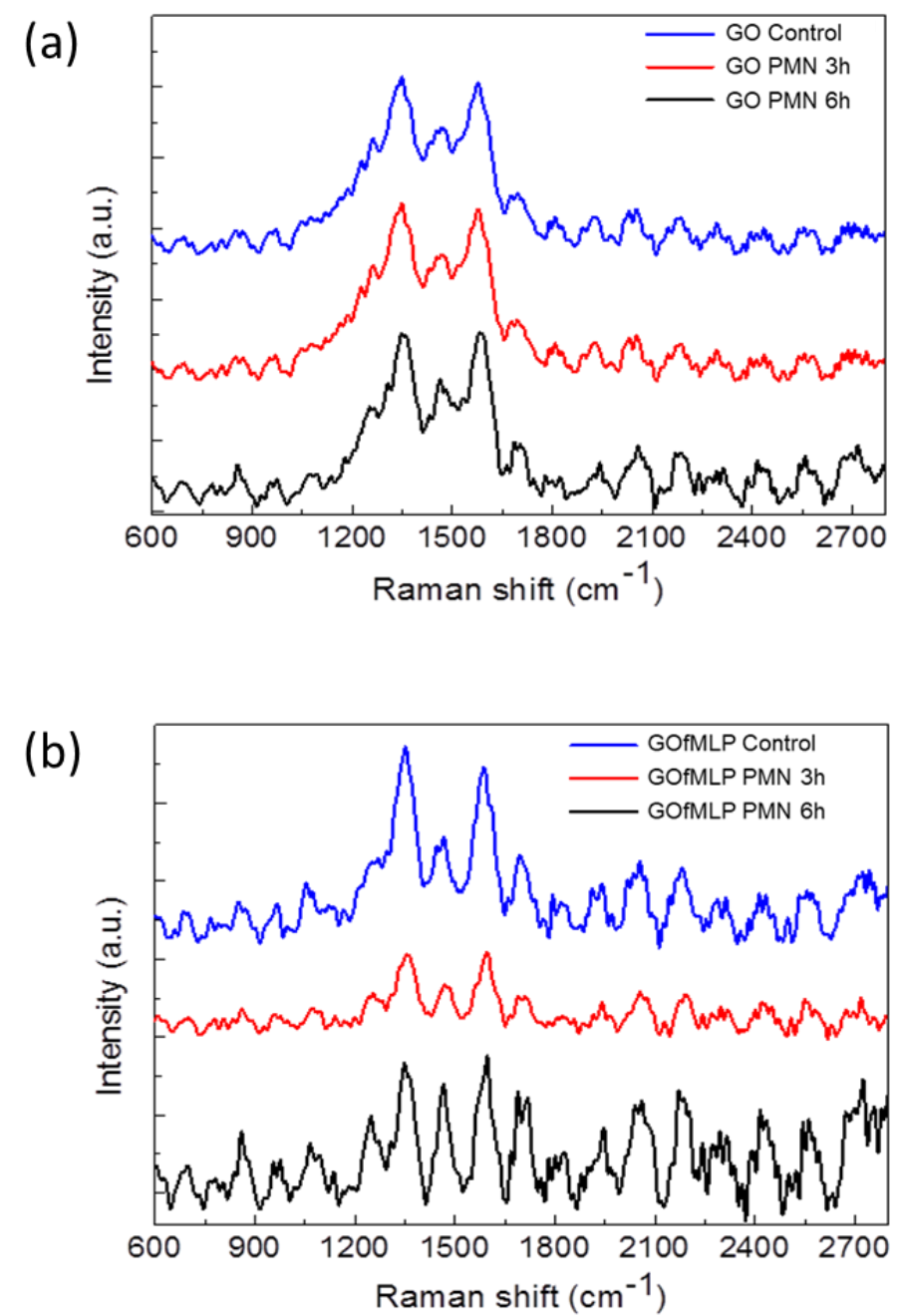

Figure 5. Neutrophil degradation of GO and GOfMLP. Freshly isolated human neutrophils were exposed to $50 \mu \mathrm{g} \cdot \mathrm{mL}^{-1}$ (a) GO and (b) GOfMLP for the indicated time-points. Raman confocal microspectroscopic measurements showed biodegradation of GOfMLP as determined by a reduction in the intensity of both the $\mathrm{D}$ and $\mathrm{G}$ bands (b), while no changes were evidenced for GO alone (a). The data shown represent an average of the whole scan (i.e., 10.000 spectra per sample). 


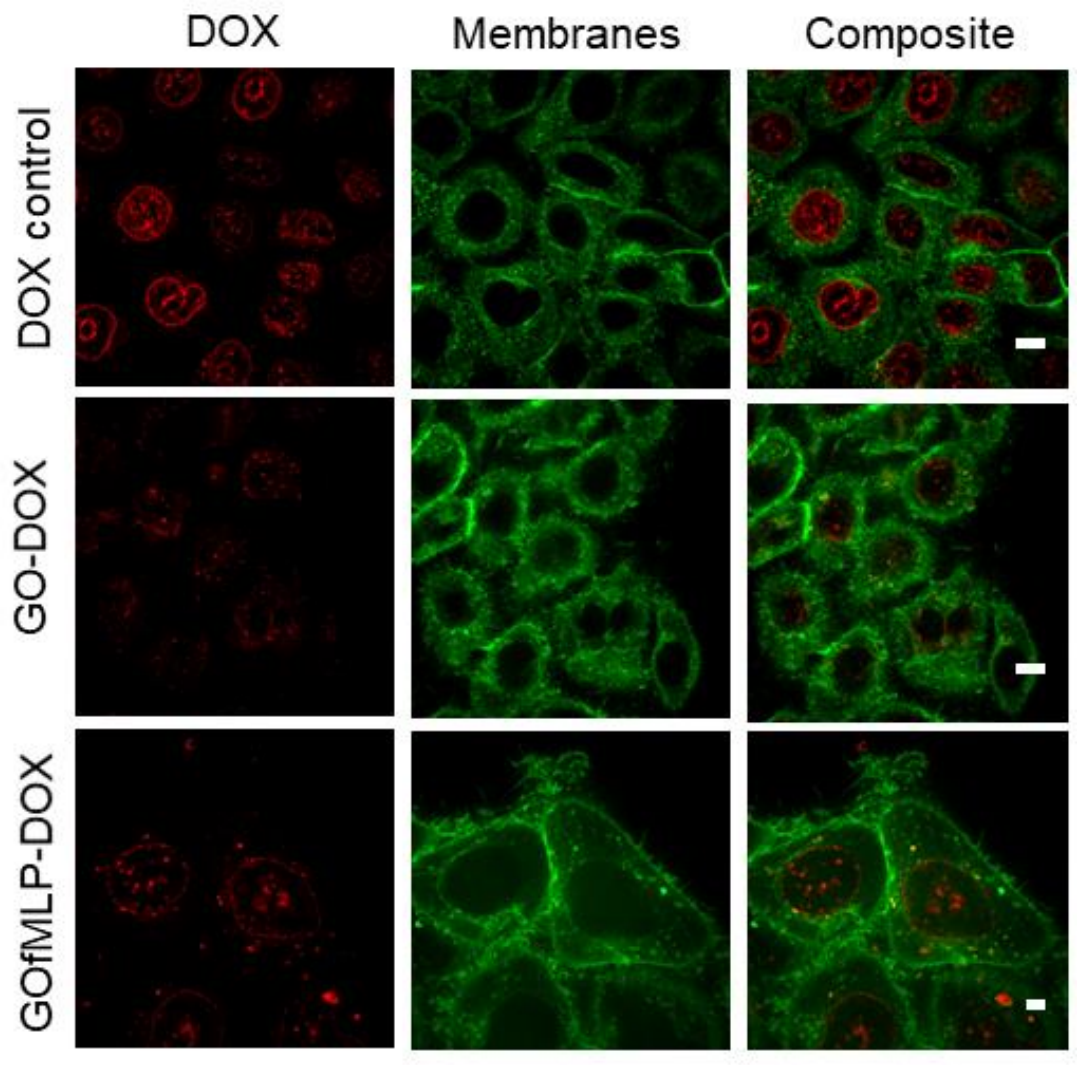

Figure 6. Confocal images of HeLa cells after $8 \mathrm{~h}$ of incubation with DOX, GO-DOX and GOfMLP-DOX at $10 \mu \mathrm{M}$. In green, membranes stained with Cell-Mask; in red, DOX. Scale bar: $10 \mu \mathrm{m}$.
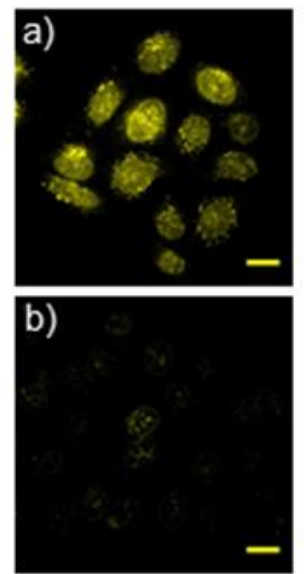

d)
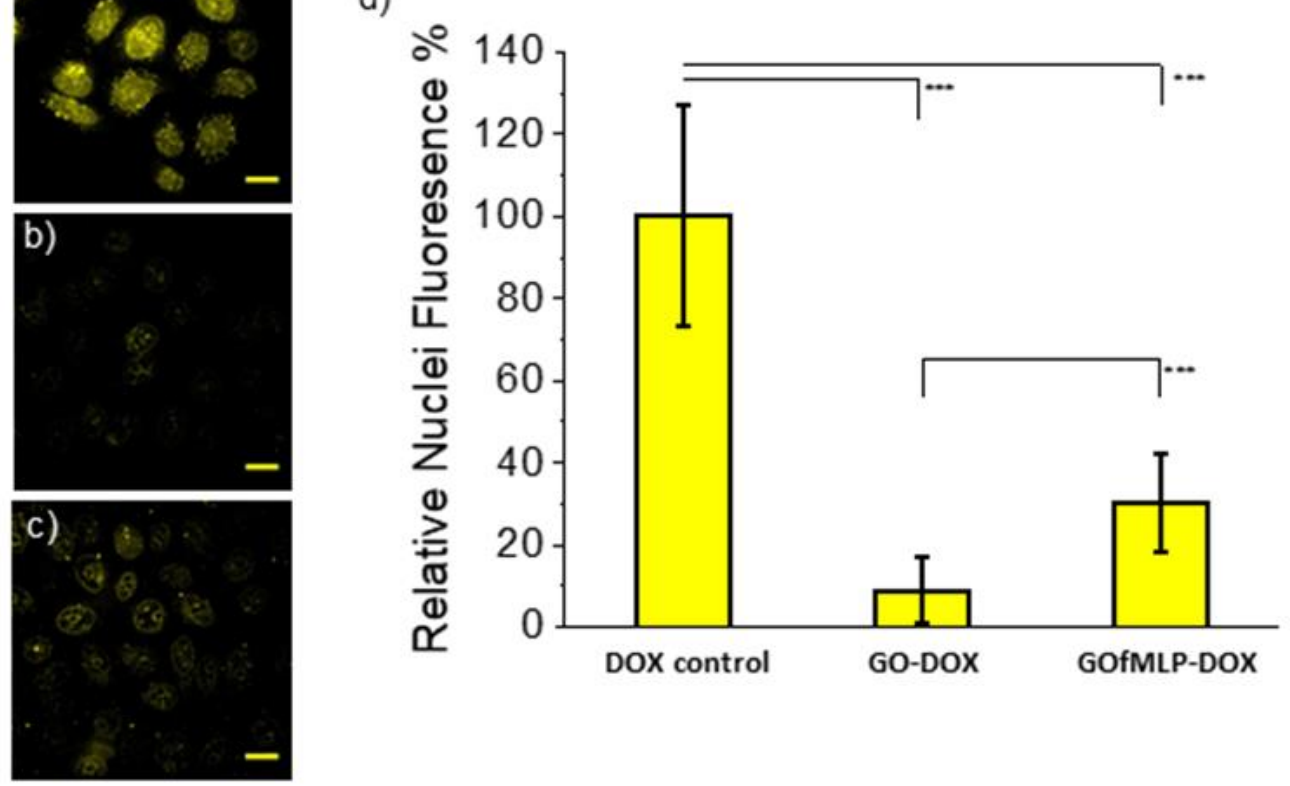

Figure 7. Confocal images of HeLa cells after $8 \mathrm{~h}$ of incubation with a) DOX, b) GO-DOX, and c) GOfMLP-DOX at $10 \mu \mathrm{M}$. d) Quantification of DOX via fluorescence intensity inside of the nuclei using FIJI software. * represents statistical significance comparing the fluorescence intensity averages (Student's t-test, ns p $>0.05, * \mathrm{p}<0.05$, ** $\mathrm{p}<0.01$, *** $\mathrm{p}<0.001, * * * * \mathrm{p}<0.0001)$. Scale bars: $20 \mu \mathrm{m}$. 
a)

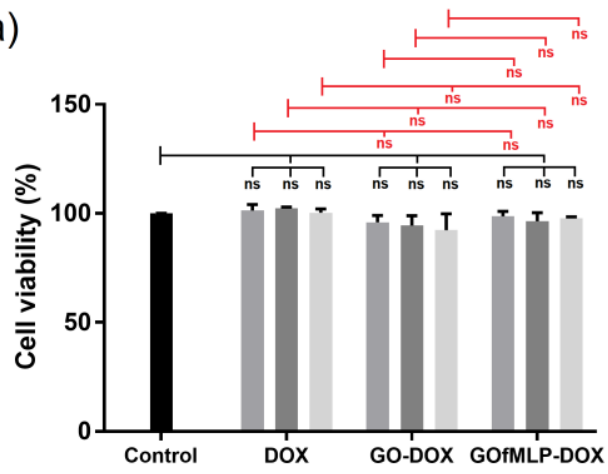

c)

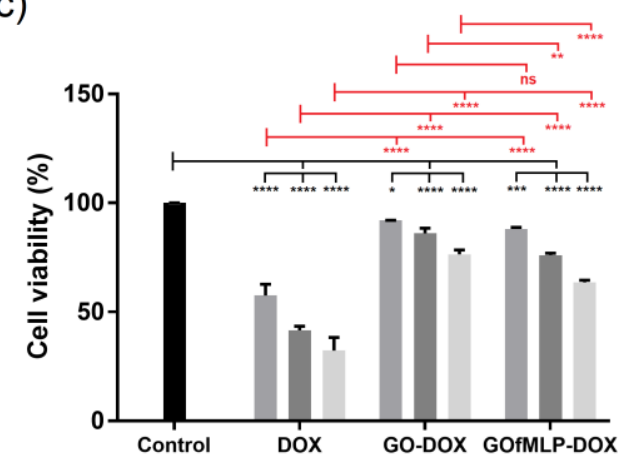

b)

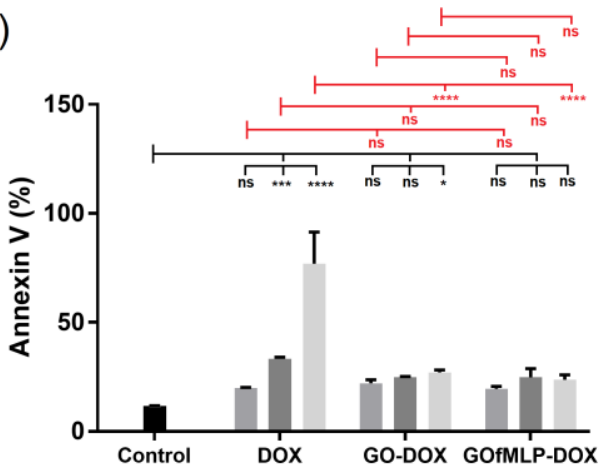

d)

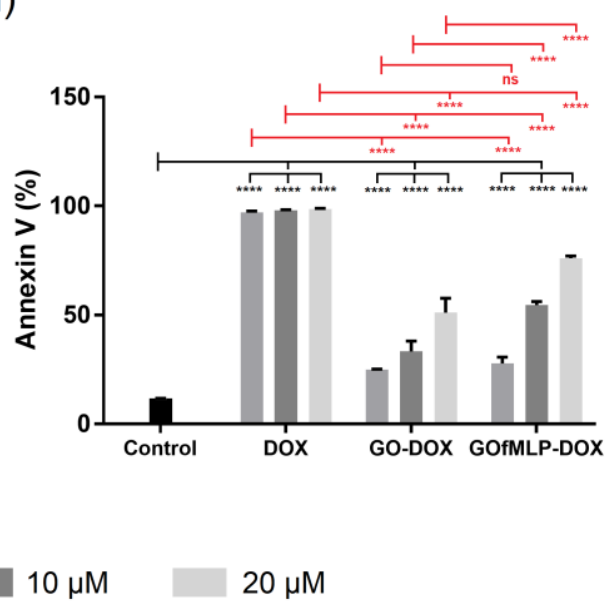

Figure 8. Cancer cell killing using nano-carriers. Evaluation of cell viability (a, c) and apoptosis, as evidenced by using the annexin V-FITC assay (b, d) in HeLa cells after $8 \mathrm{~h}(\mathrm{a}, \mathrm{b})$ and $24 \mathrm{~h}(\mathrm{c}, \mathrm{d})$ of incubation. The cells were exposed to DOX, GO-DOX, or GOfMLP-DOX, or were left untreated as a control. Data shown are mean values $\pm \operatorname{SD}(n=3)$. * (in black) shows statistically significance compared to the control. * (in red) shows significance comparing the different formulations of the drug (DOX). Two-way ANOVA followed by Bonferroni's post-test: ns $\mathrm{p}>0.05, * \mathrm{p}<0.05, * * \mathrm{p}<0.01, * * * \mathrm{p}<0.001, * * * * \mathrm{p}<0.0001$. 